\title{
Calcium deficiencies and apical hyperbranching in wild-type and the 'frost' and 'spray' morphological mutants of Neurospora crassa
}

\author{
J. WARREN DiCKeR ${ }^{*} \dagger$ and Gilbert TURIAN
} Laboratoire de Microbiologie Générale, Département de Biologie Végétale, Université de Genève, 1211 Geneva 4,
Switzerland

(Received 16 November 1989; revised 20 February 1990; accepted 26 February 1990)

\begin{abstract}
The role of $\mathrm{Ca}^{2+}$ in the maintenance of apical dominance in Neurospora crassa was investigated. In the presence of the calcium-channel blocker verapamil (1 mM), wild-type hyphal tips demonstrated enhanced branching which led to a fan-like pattern of growth, similar to that seen in certain of the morphological mutants of $N$. crassa such as 'frost' and 'spray'. In verapamil-treated hyphae, unlike untreated controls, $\mathrm{Ca}^{2+}$ was not observed in hyphal tips by fluorescence microscopy and the exaggerated branching pattern could be corrected by the addition of $10 \mathrm{mM}-\mathrm{Ca}^{2+}$. Studies using the morphological mutants 'frost' and 'spray', which grow typically on minimal medium with a branching pattern quite similar to verapamil-treated wild-type, also failed to demonstrate $\mathrm{Ca}^{2+}$ in hyphal tips. Exogenously added $\mathrm{Ca}^{2+}(50-500 \mathrm{~mm})$ almost completely corrected the abnormal branching seen in these mutants, converting them to an essentially wild-type appearance. These observations suggest that low $\mathrm{Ca}^{2+}$ levels, induced in the wild-type by verapamil, and constitutive in the mutants, are responsible for the abnormal branching patterns.
\end{abstract}

\section{Introduction}

In moulds, growth proceeds by both polarized linear extension of hyphal tips and branching, the net result of which determines colony morphology and relates to the efficiency with which the organism exploits its environment. Among the many morphological mutants of Neurospora, a substantial number characteristically exhibit increased and/or altered branching patterns which lead to novel colony morphologies as suggested by names such as 'snowflake', 'doily', 'spray', 'frost' and others. In several mutants, the increased branching occurs apically and is so profuse that it produces fan-like patterns at the edge of advancing colonies. Wild-type Neurospora hyphae, by contrast, like many other tipgrowing organisms, extend in a linear, highly polarized manner with branches occurring mainly subapically.

For some time it has been known that the structural polarity of the fungal hyphae is accompanied by an electrical polarity (Slayman \& Slayman, 1962; Jaffe \& Nuccitelli, 1974) and it is now known that many organisms and tissues that extend by polarized apical extension drive an electrical current through themselves.

$\dagger$ Present address: Department of Biology, Miami-Dade Community College, 11011 SW 104 Street, Miami, Florida 33176, USA.

Abbreviation: CTC, chlortetracycline.
Invariably positive electrical current enters the apical region and exits distally (Gow, 1984). This has been found to be true not only for many fungi but also in pollen tubes, algal rhizoids, plant roots, root hairs, and nerve axons and dendrites (Weisenseel et al., 1975, 1979; Robinson \& Jaffe, 1975; Freeman et al., 1985). In the water mould Achlya bisexualis, the current appears to be carried by protons which are expelled by a protontranslocating ATPase in the distal plasma membrane and enter apically in symport with amino acids (Kropf $e t$ al., 1984; Gow et al., 1984; Kropf, 1986). Thus, in $A$. bisexualis the elongating hyphae can be envisaged as a highly polarized, spatially extended chemiosmotic system which drives an electrical current through itself (Harold et al., 1985a, b). In Neurospora also, the circulating current appears to be carried principally by protons (McGillivray \& Gow, 1987; Takeuchi et al., 1988). It is now widely believed that these ion currents are closely involved with, or possibly essential to the mechanism or mechanisms which bring about polarized growth in tip growing systems.

During hyphal extension in fungi, fusion of cellmembrane and cell-wall precursors occurs only at the growing apex which must therefore be strong enough to resist turgor pressure, the driving force for expansion, but at the same time be sufficiently flexible to allow the 
expansion. Arrays of F-actin have been found to be concentrated in the tips of a variety of fungal hyphae (Hoch \& Staples, 1983; Marks \& Hyams, 1985; Tucker $e t$ al., 1986; Runeberg et al., 1986; Heath, 1987) and it has been suggested that their function is to support the expanding cell wall against turgor pressure (Picton \& Steer, 1982).

During growth, Golgi-derived membrane-bound vesicles containing wall-synthesizing materials stream forward, exocytosing at the tip (Picton \& Steer, 1982). This polarized movement of precursor vesicles has been variously ascribed to an electrophoretic mechanism whereby charged vesicles would follow the electrical gradient electrophoretically to the tip (Jaffe, 1977; Jaffe et al., 1974; Quatrano, 1978), although this view has been questioned (Kropf et al., 1983), or to mechanisms whereby vesicles would interact with elements of the cytoskeleton in a polarized manner, possibly via actinmyosin interactions like those known to be involved in the translocation of cytoplasm during amoeboid movement (Condeelis \& Taylor, 1977; Hellewell \& Taylor, 1979).

Numerous studies have assigned $\mathrm{Ca}^{2+}$ a role in the polarized apical extension of tip growing cells. $\mathrm{Ca}^{2+}$ gradients, maximal apically, exist in a variety of instances including root hairs, pollen tubes, algae and fungi (Reiss \& Herth, 1978, 1979; Jaffe et al., 1975). $\mathrm{Ca}^{2+}$ ions may be important to the polarized transport of precursor vesicles and their fusion during apical growth, and $\mathrm{Ca}^{2+}$ is known to influence the structure and rigidity of the actin network in the hyphal tip (Jackson \& Heath, 1989).

Several studies have reported morphological effects in fungi, specifically modifications of apical extension and branching patterns in response to disturbances of $\mathrm{Ca}^{2+}$ levels brought about either by withholding $\mathrm{Ca}^{2+}$ from media or by the use of calcium ionophores (Reissig \& Kinney, 1983; Harold \& Harold, 1986; Schmid \& Harold, 1988; McGillivray \& Gow, 1987).

The present study explores further the connection between $\mathrm{Ca}^{2+}$ and apical morphology in Neurospora.

\section{Methods}

Neurospora crassa strains 740R231A (wild-type FGSC 987), B110 ('frost', FGSC 103) and B132 ('spray', FGSC 68) were obtained from the Fungal Genetics Stock Center (University of Kansas Medical Center, Kansas City, Kansas, USA). Stocks were maintained on minimal medium (MM; Westergaard \& Mitchell, 1947), pH 6.0, at $25^{\circ} \mathrm{C}$. In addition to sucrose, $\mathrm{KNO}_{3}$, trace elements and biotin, this medium contains the following $\left(\mathrm{g} \mathrm{l}^{-1}\right): \mathrm{KH}_{2} \mathrm{PO}_{4}, 2 \cdot 0 ; \mathrm{MgSO}_{4} \cdot 7 \mathrm{H}_{2} \mathrm{O}$, $1 \cdot 0 ; \mathrm{NaCl}, 0 \cdot 1 ; \mathrm{CaCl}_{2} \cdot 2 \mathrm{H}_{2} \mathrm{O}, 0 \cdot 1$. Total $\mathrm{Ca}^{2+}$ concentration, including that contributed by other components of the medium, was approximately $6.8 \mathrm{~mm}$, and was added directly. Hyphae for fluorescence observations were grown on small dialysis membrane squares of about
$5 \mathrm{~mm} \times 5 \mathrm{~mm}$ overlying Westergaard \& Mitchell solid MM in which added $\mathrm{Ca}^{2+}$ had been reduced to one-tenth the normal supplement. This level allowed normal growth of the wild-type measured as either production of dry weight or rate of hyphal extension and did not affect branching. The total $\mathrm{Ca}^{2+}$ concentration, including that from the other components of the medium, was approximately $0.68 \mathrm{mM}$. Except for the maintenance of stocks as described above, unless otherwise noted, MM throughout this study contained this reduced amount of $\mathrm{Ca}^{2+}$.

When used, verapamil (Sigma) was at a concentration of $1 \mathrm{~mm}$. For visualization of membrane-associated $\mathrm{Ca}^{2+}$, dialysis membrane cultures approximately $12 \mathrm{~h}$ old were lifted from the agar surface, transferred to liquid medium of the same type on microscope slides without coverslips, and allowed to continue incubation directely on the slide with frequent gentle changes of the medium by Pasteur pipette for approximately $4 \mathrm{~h}$ to produce fresh vigorous growth. Chlortetracycline (CTC) $(100 \mu \mathrm{M})$ dissolved in the incubation medium was then applied directly to the undisturbed culture after excess medium had been removed. After approximately $5 \mathrm{~min}$ of contact with the CTCcontaining medium, a coverslip was placed on the culture and the slide viewed immediately. In one case (Fig. 1c) wild-type hyphae (Fig. 1b) were exposed to $1 \mathrm{mM}$-verapamil. The CTC-containing $\mathrm{MM}$ was exchanged for CTC-containing MM containing $1 \mathrm{mM}$-verapamil. A Leitz Orthoplan epi-illumination microscope equipped with NPL Fluotar optics and selective filter combinations was used for viewing. Photographs were taken on Kodak tri-X or Ilford HP5 black-and-white film, in either case rated at 1600 ASA.

\section{Results}

Young, active wild-type hyphae growing in the liquid minimal medium on microscope slides as described above grow with relatively little branching and fluoresce brightly shortly after the addition of $100 \mu \mathrm{M}-\mathrm{CTC}$ (Fig. $1 a, b)$. Upon replacement of the CTC-containing medium with another of the same composition but containing $1 \mathrm{mM}$-verapamil in addition to CTC, the hyphal tips immediately began to swell and branch and simultaneously the fluoresence dissipated. Fig. 1(c) shows the effects of $1 \mathrm{mM}$-verapamil approximately $15 \mathrm{~min}$ after its application and was photographed with visible light as the fluorescence by this time had completely dissipated. Fig. 2(b) illustrates the typical morphology of wild-type Neurospora growing on solid MM (0.68 $\left.\mathrm{mM}^{-\mathrm{Ca}^{2+}}\right)$ supplemented with $1 \mathrm{mM}$-verapamil and might be thought of as a later stage of the process seen beginning in Fig. 1(c). Such hyphal morphology with its exaggerated tip branching is highly reminiscent of certain of the known morphological mutants of Neurospora, notably 'frost' (Fig. 4a) and 'spray' (Fig. 7a). The verapamil-induced branching pattern was stable for several days as the colony grew across the Petri plate. Despite repeated attempts, we were unable to demonstrate membrane-associated $\mathrm{Ca}^{2+}$ in these verapamiltreated wild-type hyphae using CTC.

$\mathrm{Ca}^{2+}$ ions are thought to be important to the maintenance of apical dominance. Application of the ionophore A23187 in Neurospora, even though earlier reports are conflicting (Cheung, 1980; Reissig \& Kinney, 

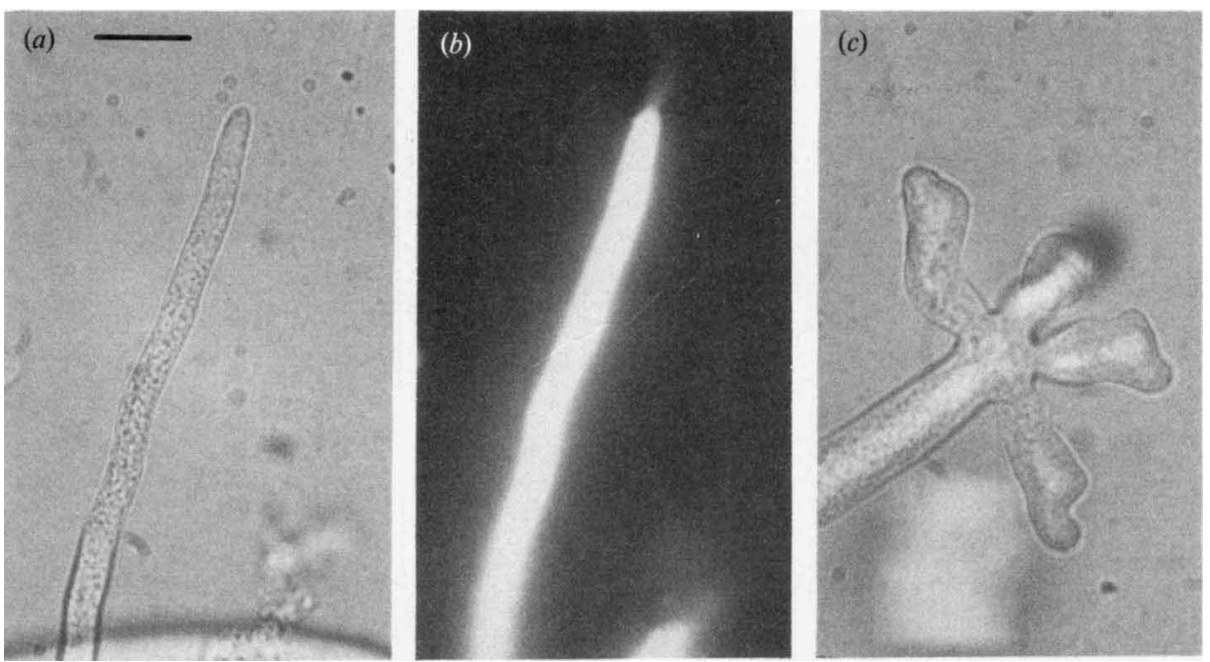

Fig. 1. Wild-type growing in MM with $100 \mu \mathrm{M}$-CTC. (a) Photomicrograph taken with visible light. (b) Same as (a) but showing CTC fluorescence. (c) Photomicrograph taken approximately $15 \mathrm{~min}$ after the addition of $1 \mathrm{~mm}$-verapamil. CTC fluorescence is lost at this stage. Bar, $10 \mu \mathrm{m}$.
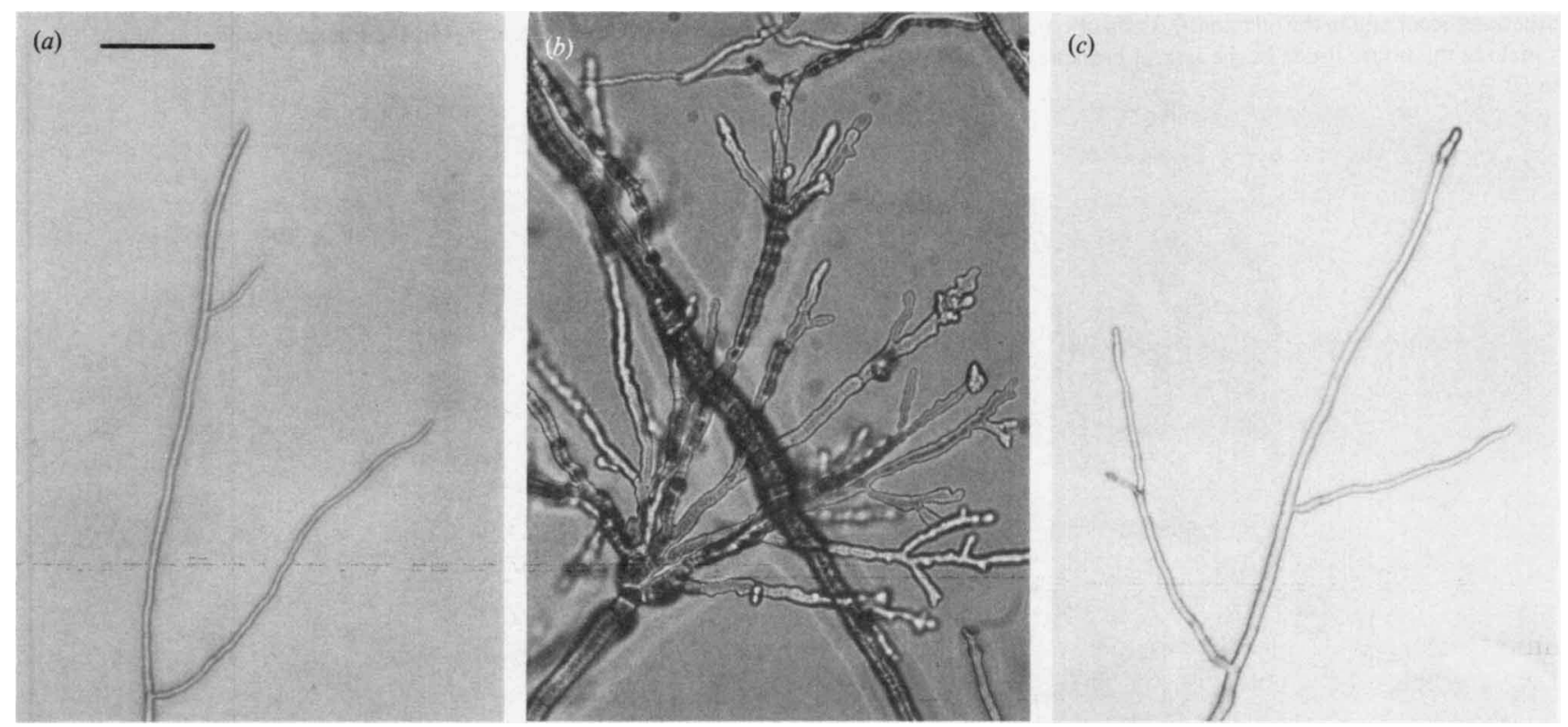

Fig. 2. Wild-type. (a) Typical morphology on MM. (b) MM plus $1 \mathrm{mM-verapamil.} \mathrm{(c)} \mathrm{MM} \mathrm{plus} 1$ mM-verapamil and $50 \mathrm{mM}-\mathrm{Ca}^{2+}$. Bar, $50 \mu \mathrm{m}$.

1983), apparently causes an immediate partial loss of intracellular $\mathrm{Ca}^{2+}$ (measured as loss of ${ }^{45} \mathrm{Ca}^{2+}$ from preloaded cells) concomitant with a loss of CTC fluorescence and a transient increase in branching at the hyphal apex (Schmid \& Harold, 1988). It seemed reasonable then that the increased branching seen as a result of verapamil treatment might also be due to a lack of $\mathrm{Ca}^{2+}$, especially since added calcium largely overcame the effects of the verapamil (Fig. $2 c$, Fig. 3). The system could thus fulfil the criteria of Jaffe (1980) for a $\mathrm{Ca}^{2+}$ controlled process as follows: 1 , the event, namely active polarized hyphal extension, is accompanied by an increase in intracellular $\mathrm{Ca}^{2+} ; 2$, blockage of the crease in the cytoplasmic $\mathrm{Ca}^{2+}$ concentration by calciumchannel blockers prevents normal apical extension, leading to hyperbranching; and 3, exogenous application of an elevated level of $\mathrm{Ca}^{2+}$ causes a return to normal branching and largely corrects apical extension rates (see Fig. 3).

Because of the similarity of branching patterns 


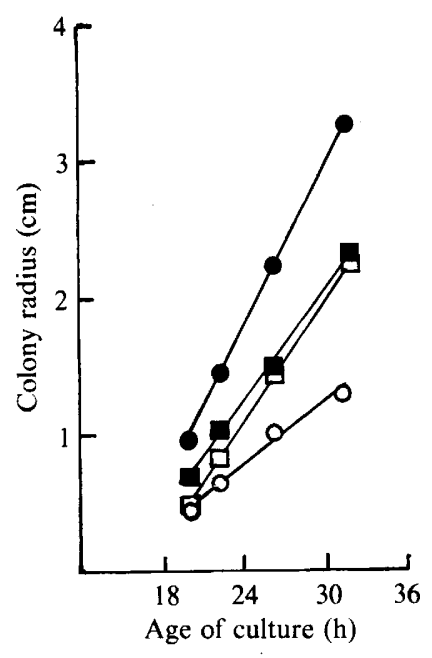

Fig. 3. Reversal of verapamil effects in the wild-type by the addition of $\mathrm{Ca}^{2+}$. Experiments were done in duplicate. At least 50 hyphal axes were scored in each experiment. Control cultures growing on solid MM (0.7); O, MM plus $1 \mathrm{mM}$-verapamil (8.2); $\mathbf{0}$, MM plus $1 \mathrm{mM-}$ verapamil and $10 \mathrm{mM}-\mathrm{Ca}^{2+}(0.9) ; \square, \mathrm{MM}$ plus $1 \mathrm{mM}$-verapamil and $50 \mathrm{mM}-\mathrm{Ca}^{2+}(1 \cdot 0)$. Numbers in parentheses indicate the total number of bifurcations occurring in the terminal $0.3 \mathrm{~mm}$ of typical leading hyphae and include the bifurcations in the lateral branches found within this zone.

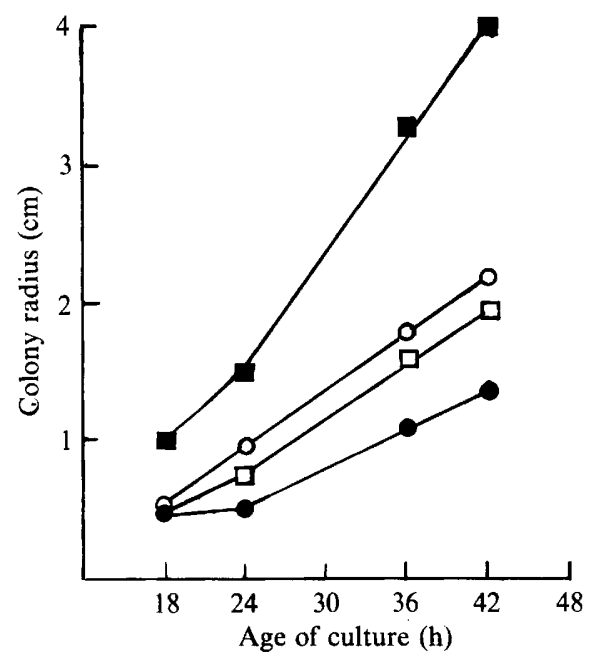

Fig. 5. Effects of added $\mathrm{Ca}^{2+}$ on colony extension rates and terminal branching in 'frost'. Experiments were done in duplicate. At least 50 hyphal axes were scored in each experiment., $\mathrm{MM}(23) ; \bigcirc, \mathrm{MM}$ plus $10 \mathrm{mM}-\mathrm{Ca}^{2+}(10) ; \mathbf{M}$, M plus $50 \mathrm{mM}-\mathrm{Ca}^{2+}(3 \cdot 1) ; \square, \mathrm{MM}$ plus $500 \mathrm{mM}-$ $\mathrm{Ca}^{2+}(3 \cdot 2)$. Numbers in parentheses indicate the total number of bifurcations occurring in the terminal $0.3 \mathrm{~mm}$ of typical leading hyphae and include the bifurcations in the lateral branches found within this zone.

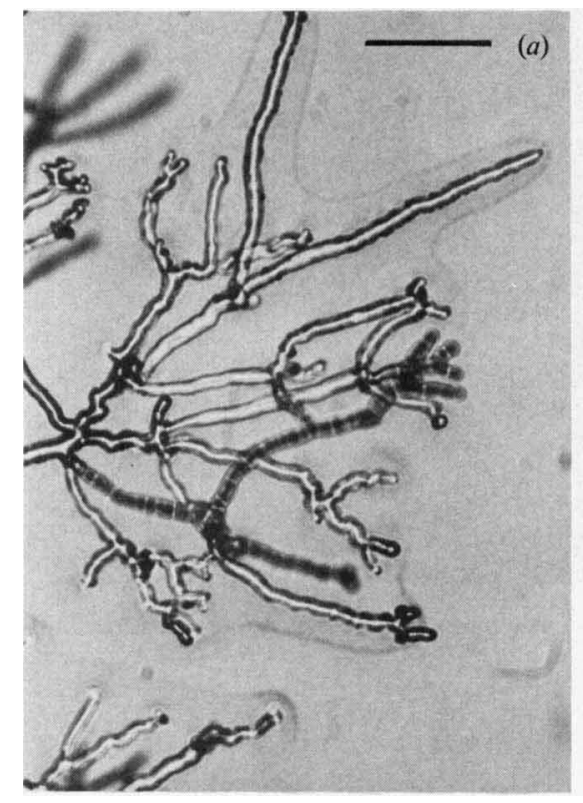

Fig. 4. 'Frost'. (a) Typical morphology on MM. (b) MM plus $500 \mathrm{mM}-\mathrm{Ca}^{2+}$. Bar, $50 \mu \mathrm{m}$. between verapamil-treated wild-type and the two morphological mutants, an attempt was made to demonstrate $\mathrm{Ca}^{2+}$ in hyphal tips of 'frost' and 'spray'. Again, despite repeated attempts, we never observed more than a faint

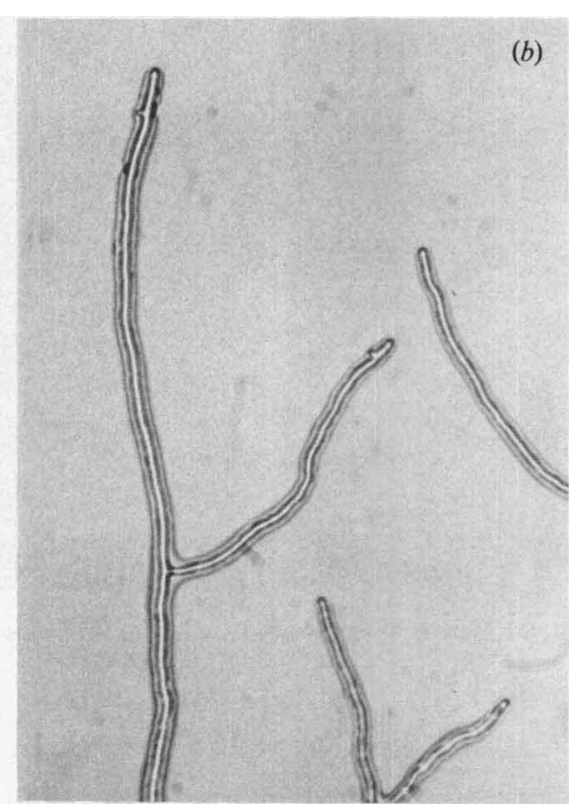

fluorescence in 'spray' and even less in the hyphae of 'frost'.

As with the verapamil-treated wild-type cultures, calcium additions $(50-500 \mathrm{mM})$ to the growth medium of 

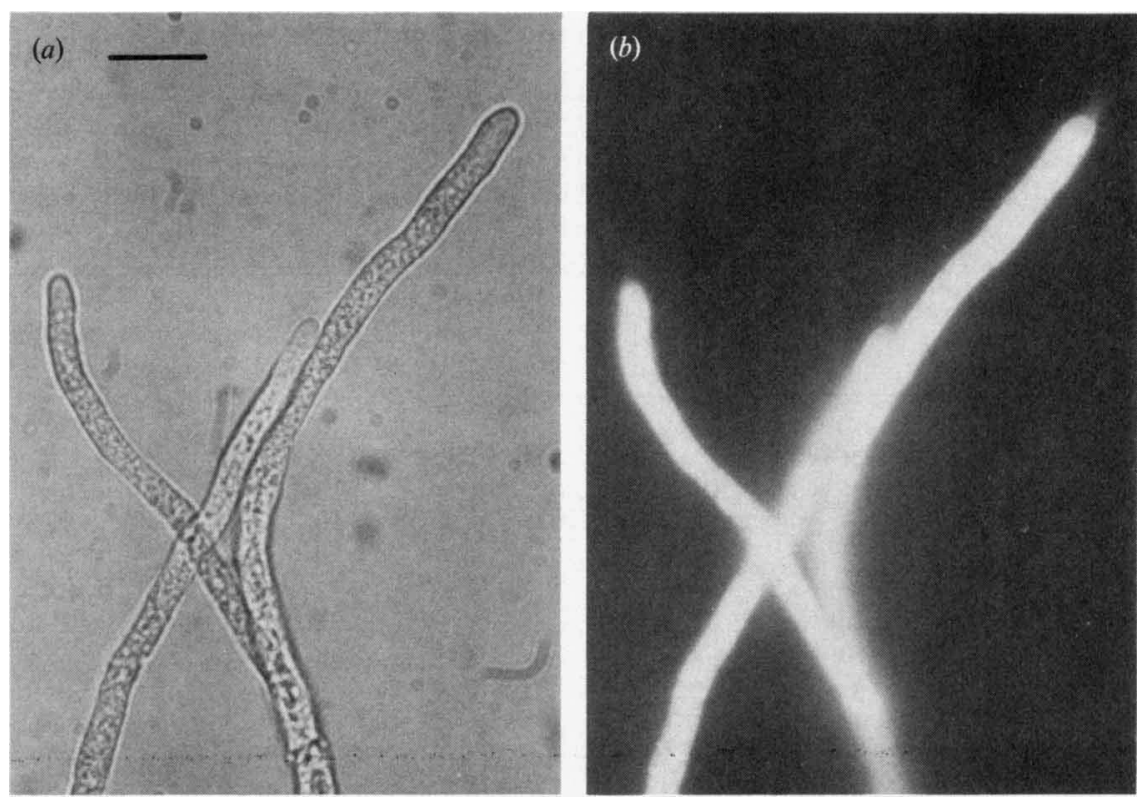

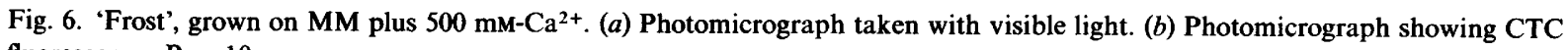
fluorescence. Bar, $10 \mu \mathrm{m}$.
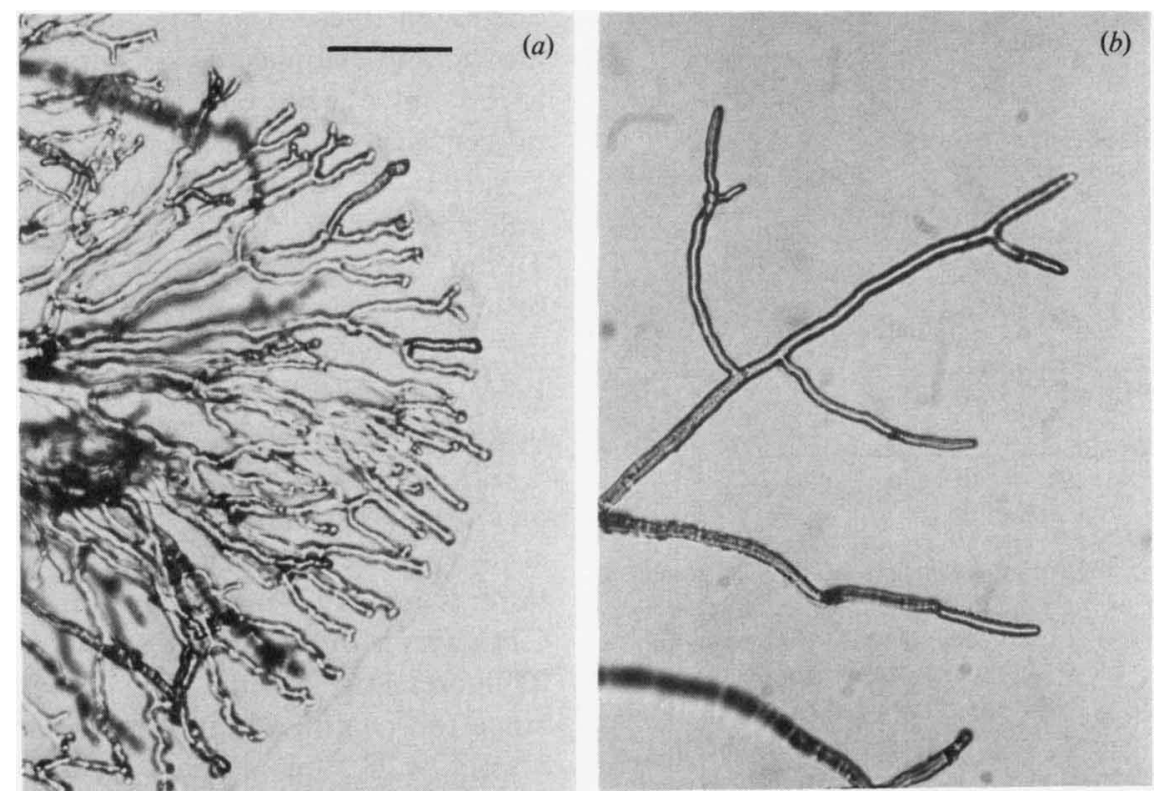

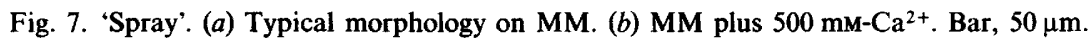

the morphological mutants similarly corrected the abnormal branching. Figs 5 and 8 and Table 1 show the effects of exogenously added calcium on hyphal extension rates and terminal branching in 'frost' and 'spray', respectively. Figs 4 and 7 show hyphal tip morphology of the mutants in the presence of $500 \mathrm{~mm}-\mathrm{Ca}^{2+}$. With 'frost', a $50 \mathrm{~mm}-\mathrm{Ca}^{2+}$ supplement was equally effective in correcting the mutant phenotype. Along with the corrected hyphal morphology and branching patterns, it was possible to detect membrane-associated $\mathrm{Ca}^{2+}$ by CTC fluorescence in the mutants (Fig. 6; data not shown for 'spray'). The fact that exogenously added $\mathrm{Ca}^{2+}$ corrected the abnormal branching both in the mutants and in the verapamil-treated wild-type suggests that their 
Table 1. Summary of growth rates and hyphal tip branching

Growth rates were obtained by averaging the rates at which colonies advanced on Petri plates from $18 \mathrm{~h}$ post-inoculation to $42 \mathrm{~h}$ post-inoculation ( $32 \mathrm{~h}$ post-inoculation in the case of the wild-type). Branching data were obtained by counting the total number of bifurcations occurring in the terminal $0.3 \mathrm{~mm}$ of typical leading hyphae and include the bifurcations in the lateral branches found within this zone. At least 50 hyphal axes were scored in each case.

\begin{tabular}{|c|c|c|c|}
\hline Strain & Medium & $\begin{array}{l}\text { Hyphal extension } \\
\text { rate }\left(\mathrm{mm} \mathrm{h}^{-1}\right)\end{array}$ & $\begin{array}{c}\text { Mean total } \\
\text { bifurcations in } \\
\text { terminal } 0 \cdot 3 \mathrm{~mm}\end{array}$ \\
\hline Wild-type & $\begin{array}{l}\text { MM } \\
M M+1 \text { mM-verapamil } \\
\text { MM + } 1 \text { mM-verapamil + } 10{\mathrm{mM}-\mathrm{Ca}^{2+}}^{2+} \\
\mathrm{MM}+1 \mathrm{mM} \text {-verapamil }+50 \mathrm{mM}^{-\mathrm{Ca}^{2+}}\end{array}$ & $\begin{array}{l}1.92 \\
0 \cdot 67 \\
1 \cdot 30 \\
1 \cdot 50\end{array}$ & $\begin{array}{l}0 \cdot 7 \\
8 \cdot 2 \\
0 \cdot 9 \\
1 \cdot 0\end{array}$ \\
\hline 'Frost' & $\begin{array}{l}\mathrm{MM} \\
\mathrm{MM}+10 \mathrm{mM}-\mathrm{Ca}^{2+} \\
\mathrm{MM}+50 \mathrm{mM}-\mathrm{Ca}^{2+} \\
\mathrm{MM}+500 \mathrm{mM}-\mathrm{Ca}^{2+}\end{array}$ & $\begin{array}{l}0 \cdot 40 \\
0 \cdot 72 \\
1 \cdot 24 \\
0 \cdot 60\end{array}$ & $\begin{array}{r}23 \cdot 0 \\
10 \cdot 0 \\
3 \cdot 1 \\
3 \cdot 2\end{array}$ \\
\hline 'Spray' & $\begin{array}{l}\mathrm{MM} \\
\mathrm{MM}+10 \mathrm{mM}-\mathrm{Ca}^{2+} \\
\mathrm{MM}+50 \mathrm{mM}-\mathrm{Ca}^{2+} \\
\mathrm{MM}+500 \mathrm{mM}-\mathrm{Ca}^{2+}\end{array}$ & $\begin{array}{l}0 \cdot 38 \\
0 \cdot 67 \\
0 \cdot 94 \\
0 \cdot 65\end{array}$ & $\begin{array}{c}\text { Profuse }(>25) \\
\text { Profuse }(>25) \\
12 \cdot 0 \\
2 \cdot 7\end{array}$ \\
\hline
\end{tabular}

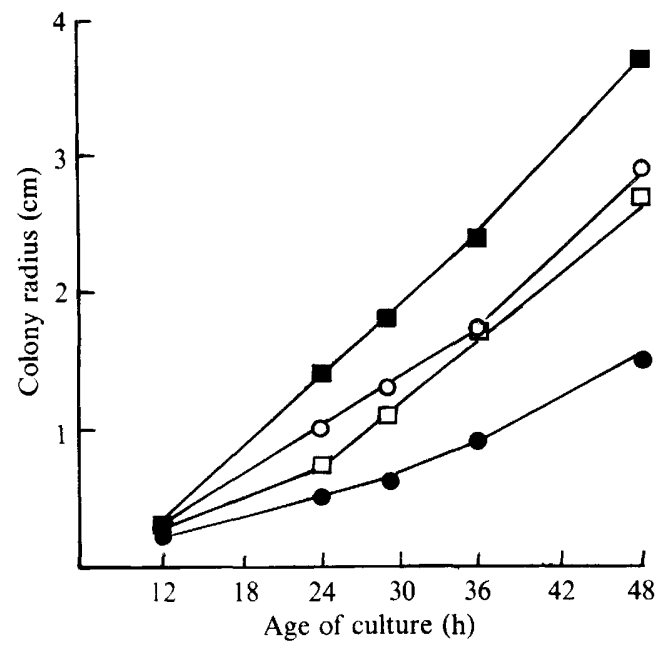

Fig. 8. Effects of added $\mathrm{Ca}^{2+}$ on colony extension rates and terminal branching in 'spray'. Experiments were done in duplicate. At least 50 hyphal axes were scored in each experiment. $\mathrm{MM}$ (branching too profuse to count accurately); $\mathrm{O}, \mathrm{MM}$ plus $10 \mathrm{mM}-\mathrm{Ca}^{2+}$ (branching too profuse to count accurately);, $\mathrm{MM}$ plus $50 \mathrm{mM}-\mathrm{Ca}^{2+}(12) ; \square, \mathrm{MM}$ plus $500 \mathrm{mM}-\mathrm{Ca}^{2+}(2 \cdot 7)$. Numbers in parentheses indicate the total number of bifurcations occurring in the terminal $0.3 \mathrm{~mm}$ of typical leading hyphae and include the bifurcations in the lateral branches found within this zone.

morphological similarities as well as the underlying physiological causes are more than superficial or accidental.

\section{Discussion}

An ever-increasing number of processes are being found to be under the control of $\mathrm{Ca}^{2+}$. We propose that the morphological mutants 'frost' and 'spray' and wild-type hyphae in the presence of verapamil are at least partially deprived of $\mathrm{Ca}^{2+}$ and may be deficient to at least some degree in these $\mathrm{Ca}^{2+}$-mediated processes. Polarized growth and cytoplasmic streaming are processes known to be influenced by $\mathrm{Ca}^{2+}$. Also, $\mathrm{Ca}^{2+}$ is known to influence the arrays of F-actin that form an apical cap in a variety of fungi (Jackson \& Heath, 1989) and to influence turgor pressure in Neurospora (Slayman \& Tatum, 1965). Links exist between $\mathrm{Ca}^{2+}$ and other second-messenger systems such as cyclic AMP, calmodulin, diacylglycerol and probably cytoplasmic $\mathrm{pH}$ (Busa, 1986). Thus the disruption of $\mathrm{Ca}^{2+}$ levels may have farreaching results.

CTC fluorescence demonstrates the presence of membrane-associated $\mathrm{Ca}^{2+}$ although its absence may not always represent the reverse (Caswell, 1979; Blinks et al., 1982; Kauss, 1987). The $\mathrm{Ca}^{2+}$ ions form a complex with CTC which then associates with adjacent membranes, its fluorescence simultaneously increasing significantly. Since the complex is in equilibrium with $\mathrm{Ca}^{2+}$ in the cytosol, CTC fluorescence probably does give some indication of intracellular $\mathrm{Ca}^{2+}$ although variations in intracellular $\mathrm{pH}$ and other variables may confuse the picture.

The possibility that the fluorescence observed in this study might be associated with the cell wall is judged unlikely, because of the rapidity with which it can dissipate, the fact that the more distal portions of hyphae do not fluoresce significantly, that the mutants do not fluoresce, and that the fluorescence is greatest at the apex where the wall is thinnest. It is also difficult to imagine how verapamil would prevent $\mathrm{Ca}^{2+}$ from being available 
extracellularly or how it would cause rapid dissipation of the CTC fluorescence as described in this study if the fluorescing material were attached to the cell wall. Nevertheless, external $\mathrm{Ca}^{2+}$ is known to influence cell wall plasticity in higher plants, low levels of $\mathrm{Ca}^{2+}$ favouring increased plasticity (Tagawa \& Bonner, 1957). In Neurospora, low $\mathrm{Ca}^{2+}$ levels favoured distorted irregularly shaped hyphae (Jackson \& Heath, 1989) and it was suggested that in the absence of $\mathrm{Ca}^{2+}$ or in the presence of very low levels of $\mathrm{Ca}^{2+}$ the cell wall may be too plastic to resist osmotic forces and prevent swelling. Schmid \& Harold (1988) have also suggested that surface-bound $\mathrm{Ca}^{2+}$ may be important to the generation of normal hyphal morphology.

In the present study, along with an immediate morphological effect, verapamil caused an immediate loss of CTC-demonstrated membrane-associated calcium, acting presumably by blocking channels at the hyphal apex through which calcium may move down the electrochemical gradient to enter the hyphae. Antagonism and relief of the morphological effects caused by verapamil by exogenously added calcium seems to support this view. Many substances however cause increased apical branching in fungi and the existence of $\mathrm{Ca}^{2+}$ channels in Neurospora has been questioned (Takeuchi et al., 1988).

In Botrytis cinerea, 31 different antibiotics and inhibitors have been reported as causing morphological effects, most of these thought to be acting at the level of the cell membrane (Baráthová \& Betina, 1976). A common type of effect seen was increased apical branching, in some cases very similar to that reported in this study. Many of the same substances were found to produce similar morphological effects in Neurospora (Betina et al., 1975), and in this connection it is interesting to note that the 'frost' mutant, too, is thought to have membrane defects (Scott et al., 1974; Scott, 1976). The question can be asked whether these various substances capable of causing increased apical branching will all cause a loss of CTC fluorescence as verapamil does. On the basis of this study, it seems quite likely in many cases that this will prove to be true. Moreover it seems possible that calcium transport could be deficient by a variety of mechanisms in addition to the specific blocking of $\mathrm{Ca}^{2+}$ channels if indeed that is the mechanism by which verapamil brings about the morphological effects reported in this study.

Studies have sought to determine whether $\mathrm{Ca}^{2+}$ might carry all or part of the transhyphal current. With very low levels of free $\mathrm{Ca}^{2+}$ in the medium of Neurospora, transhyphal currents fluctuated wildly, on occasions even reversing (Takeuchi et al., 1988). McGillivray \& Gow (1987) found that withholding $\mathrm{Ca}^{2+}$ caused an immediate cessation of apical extension and an increase of the transhyphal current. Schmid \& Harold (1988) observed a continuation of hyphal elongation subsequent to the addition of A23187, which in their experiments caused an immediate branching at hyphal tips and loss of $\mathrm{Ca}^{2+}$ as measured by loss of ${ }^{45} \mathrm{Ca}^{2+}$ from preloaded cells and loss of CTC fluorescence. They suggested that $\mathrm{Ca}^{2+}$ may be necessary for apical dominance but not for polarized extension of hyphae. In their experiments, however, less than half the preloaded ${ }^{45} \mathrm{Ca}^{2+}$ was lost and of this, most of the net loss (approximately 75\%) occurred at exactly the time the hyphal tips were branching abnormally. That these tips recovered and continued their polarized extension, to our minds, does not necessarily mean that $\mathrm{Ca}^{2+}$ is not required for polarized growth. In fact it seems possible that the recovered tips could have relatively normal $\mathrm{Ca}^{2+}$ levels even as there continued to be a small further net loss of radioactivity. In any case, by $40 \mathrm{~min}$ post-ionophore treatment, there was rapid net $\mathrm{Ca}^{2+}$ uptake.

The results reported in this study add support to arguments favouring an important role for $\mathrm{Ca}^{2+}$ in determining the morphology of the hyphal apex. Exactly how the observed $\mathrm{Ca}^{2+}$ deficiencies bring about the morphological disturbances reported here remains to be determined as does the cause or causes of the $\mathrm{Ca}^{2+}$ deficiencies in the morphological mutants. Possible sites of involvement have been mentioned earlier. Other studies have concentrated on the effects of withholding or removing $\mathrm{Ca}^{2+}$, but to our knowledge this is the first time the problem has been approached by the addition of $\mathrm{Ca}^{2+}$ to a $\mathrm{Ca}^{2+}$-deprived situation. The morphological mutants 'frost' and 'spray' grow normally in a manner very similar to verapamil-treated wild-type cultures. The failure to demonstrate $\mathrm{Ca}^{2+}$ in either of these mutants or in the verapamil-treated wild-type cultures by CTC fluorescence and the dramatic morphological effects brought about by the addition of exogenous $\mathrm{Ca}^{2+}$ both suggest that indeed low $\mathrm{Ca}^{2+}$ levels are largely responsible for the slow extension rates and the abnormal morphologies seen in both of these mutants as well as in the treated wild-type cultures. This report further implicates $\mathrm{Ca}^{2+}$ in the physiology of tip extension in fungi, identifies verapamil as a drug that may be of use in future studies, and suggests that certain of the morphological mutants of Neurospora may be deficient in their uptake of $\mathrm{Ca}^{2+}$.

We thank Dr François Barja for encouragement and valuable suggestions during the course of this work.

\section{References}

Baráthoví, H. \& Betina, V. (1976). Antibiotic-induced changes of mycelial growth of Botrytis cinerea. Folia Microbiologica 21, 355-361. 
Betina, V., JANSTOVÁ, D. \& SPIŠIAKovÁ, J. (1975). Effects of antibiotics on the life cycle of Neurospora crassa. Folia Microbiologica 20, 340-345.

Blinks, J. R., Gil Wier, W., Hess, P. \& Prendergast, F. G. (1982). Measurement of $\mathrm{Ca}^{2+}$ concentrations in living cells. Progress in Biophysics and Molecular Biology 40, 1-114.

BusA, W. B. (1986). Mechanisms and consequences of $\mathrm{pH}$-mediated cell regulation. Annual Review of Physiology 48, 389-402.

Caswell, A. H. (1979). Methods of measuring intracellular calcium. International Review of Cytology 56, 145-181.

Cheung, W. Y. (1980). Calmodulin plays a pivotal role in cellular regulation. Science 207, 19-27.

CONDEElis, J. S. \& TAYLOR, D. L. (1977). The contractile basis of amoeboid movement. V. The control of gelation, solation and contraction of extracts from Dictyostelium discoideum. Journal of Cell Biology 74, 910-927.

Freeman, J. A., Manis, P. B., Snipes, G. J., Mayes, B. N., Samson, P. C., Wikswo, J. P. \& Freeman, D. B. (1985). Steady growth cone currents revealed by a novel circularly vibrating probe. Journal of Neuroscience Research 13, 257-283.

Gow, N. A. R. (1984). Transhyphal electrical currents in fungi. Journal of General Microbiology 130, 3313-3318.

Gow, N. A. R., KROPF, D. L. \& HAROLD, F. M. (1984). Growing hyphae of Achlya bisexualis generate a longitudinal $\mathrm{pH}$ gradient in the surrounding medium. Journal of General Microbiology 130, 2967-2974.

Harold, F. M., Shreurs, W. J., Harold, R. L. \& Caldwell, J. C. (1985a). Electrobiology of fungal hyphae. Microbiological Sciences 2, 363-366.

Harold, F. M., Kropf, D. L. \& Caldwell, J. C. (1985b). Why do fungi drive an electrical current through themselves? Experimental Mycology 9, 183-186.

HAROLD, R. L. \& HAROLD, F. M. (1986). Ionophores and cytochalasins modulate branching in Achlya bisexualis. Journal of General Microbiology 132, 213-219.

Heath, I. (1987). Preservation of a labile cortical array of actin filaments in growing hyphal tips of the fungus Saprolegnia ferax. European Journal of Cell Biology 44, 10-16.

Hellewell, S. B. \& TAYLOR, D. L. (1979). The contractile basis of amoeboid movement. VI. The solation-contraction coupling hypothesis. Journal of Cell Biology 83, 633-648.

Hoch, H. C. \& STAPLes, R. C. (1983). Visualization of actin in situ by Rhodamine-conjugated phalloidin in the fungus Uromyces phaseoli. European Journal of Cell Biology 32, 52-58.

JACKSON, S. L. \& HeATH, J. B. (1989). Effects of exogenous calcium ions on tip growth, intracellular $\mathrm{Ca}^{2+}$ concentration, and actin arrays in hyphae of the fungus Saprolegnia ferax. Experimental Mycology 13, $1-12$.

JAFFE, L. F. (1977). Electrophoresis along cell membranes. Nature, London 265, 600-612.

JAFFE, L. F. (1980). Calcium explosions as triggers of development. Annals of the New York Academy of Sciences 339, 86-101.

JAFFe, L. F. \& NuCCITELl, R. (1974). An ultrasensitive vibrating probe for measuring steady electrical currents. Journal of Cell Biology 63, 614-628.

JAFFE, L. F., RoBinson, K. R. \& NUCCITELLI, R. (1974). Local cation entry and self-electrophoresis as an intracellular localization mechanism. Annals of the New York Academy of Sciences 238, 372389.

JAFFe, L. A., Weisenseel, M. H. \& JAFFe, L. F. (1975). Calcium accumulations within the growing tips of pollen tubes. Journal of Cell Biology 67, 488-492.

KaUSS, H. (1987). Some aspects of calcium-dependent regulation in plant metabolism. Annual Review of Plant Physiology 38, 47-72.

KROPF, D. L. (1986). Electrophysiological properties of Achlya hyphae: ionic currents studied by intracellular potential recording. Journal of Cell Biology 102, 1209-1216.

Kropf, D. L., Lupa, M. D., Caldwell, J. H. \& Harold, F. M. (1983). Cell polarity: endogenous ion currents precede and predict branching in the water mold Achlya. Science 220, 1385-1387.

Kropf, D. L., Caldwell, J. H., Gow, N. A. R. \& Harold, F. M. (1984). Transcellular ion currents in the water mold Achlya. Amino acid proton symport as a mechanism of current entry. Journal of Cell Biology 99, 486-496.

MaRKS, J. \& Hyams, J. S. (1985). Localization of F-actin through the cell division cycle of Schizosaccharomyces pombe. European Journal of Cell Biology 39, 27-32.

McGillivray, A. M. \& Gow, N. A. R. (1987). The transhyphal electrical current of Neurospora crassa is carried principally by protons. Journal of General Microbiology 133, 2875-2881.

Picton, J. M. \& Steer, M. W. (1982). A model for the mechanism of tip extension in pollen tubes. Journal of Theoretical Biology 98, 15-20.

Quatrano, R. (1978). Development of cell polarity. Annual Review of Plant Physiology 29, 487-510.

REISS, H. D. \& HERTH, W. (1978). Visualization of the $\mathrm{Ca}^{2+}$-gradient in growing pollen tubes of Lilium longiflorum with chlorotetracycline fluorescence. Protoplasma 97, 373-377.

REISS, H. D. \& HERTH, W. (1979). Calcium gradients in tip growing plant cells visualized by chlorotetracycline fluorescence. Planta 146, 615-621.

REISsiG, J. L. \& KinNeY, S. G. (1983). Calcium as a branching signal in Neurospora crassa. Journal of Bacteriology 154, 1397-1402.

RoBInson, K. R. \& JAFFE, L. F. (1975). Polarizing fucoid eggs drive a calcium current through themselves. Science 187, 70-72.

RuneberG, P., Raudaskoski, M. \& Virtanen, I. (1986). Cytoskeletal elements in the hyphae of the homobasidiomycete Schizophyllum commune visualized with indirect immunofluorescence and NBDphallacidin. European Journal of Cell Biology 41, 25-32.

ScHMID, J. \& HaRold, F. M. (1988). Dual roles for calcium ions in apical growth of Neurospora crassa. Journal of General Microbiology 134, 2623-2631.

ScotT, W. A. (1976). Adenosine $3^{\prime}: 5^{\prime}$-cyclic monophosphate deficiency in Neurospora crassa. Proceedings of the National Academy of Sciences of the United States of America 73, 2995-2999.

ScotT, W. A., Mishra, N. C. \& Tatum, E. L. (1974). Biochemical genetics of morphogenesis in Neurospora. Brookhaven Symposia in Biology 25, 1-18.

Slayman, C. L. \& Slayman, C. W. (1962). Measurement of membrane potentials in Neurospora. Science 136, 876-877.

Slayman, C. W. \& Tatum, E. L. (1965). Potassium transport in Neurospora. II. Measurement of steady-state potassium fluxes. Biochimica et Biophysica Acta 102, 149-169.

TAGAWA, T. \& BonNer, J. (1957). Mechanical properties of the Avena coleoptile as related to auxin and to ionic interactions. Plant Physiology 32, 207-212.

Takeuchi, Y., Schmid, J., Caldwell, J. H. \& Harold, F. M. (1988). Transcellular ion currents and extension of Neurospora crassa hyphae. Journal of Membrane Biology 101, 33-41.

TuCKer, B. E., HoCH, H. C. \& STAPLES, R. C. (1986). The involvement of F-actin in Uromyces cell differentiation: the effects of cytochalasin E and phalloidin. Protoplasma 135, 88-101.

WeisENSEEL, M. H., NuCCITELli, R. \& JAFFE, L. F. (1975). Large electrical currents traverse growing pollen tubes. Journal of Cell Biology 66, 556-567.

Weisenseel, M. H., DoRn, A. \& JAFFe, L. F. (1979). Natural H+ currents traverse growing roots of barley (Hordeum vulgare L.). Plant Physiology 64, 512-518.

WestergaARD, M. \& Mitchell, H. K. (1947). Neurospora. V. A synthetic medium favouring sexual reproduction. American Journal of Botany 34, 576-577. 